\title{
Linear and knemometric growth in the early phase of rehabilitation from severe malnutrition
}

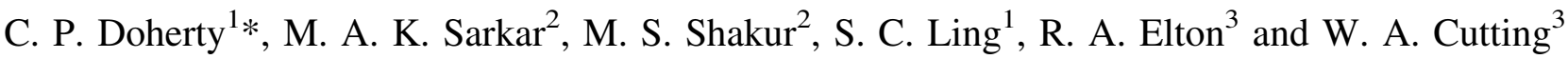 \\ ${ }^{1}$ Department of Child Health, University of Glasgow, Glasgow, UK \\ ${ }^{2}$ Bangladesh Institute of Child Health, Shishu Children's Hospital, Dhaka, Bangladesh \\ ${ }^{3}$ Department of Child Life and Health, University of Edinburgh, Edinburgh, UK \\ (Received 12 May 2000 - Revised 2 January 2001 - Accepted 5 January 2001)
}

\begin{abstract}
The relationship between ponderal, linear and lower leg growth in children recovering from severe malnutrition remains unclear. We report on the early growth of 141 severely malnourished Bangladeshi children aged 6 to 36 months of age who were followed for $90 \mathrm{~d}$. Mean (SD) weight for height (WHZ) and height for age (HAZ) catch-up growth $z$ scores over the $90 \mathrm{~d}$ were $1.6(0.85)$ and $0.47(0.325)$ respectively. Mean (SD) lower leg length growth was 10.35 (4.5) $\mathrm{mm}$. Change in HAZ was significantly associated with initial WHZ, but linear growth occurred in the presence of severe wasting and no threshold WHZ score was identified. Lower leg length gain correlated throughout with ponderal indices but with change in HAZ score only after day 45. Only initial WHZ score and maternal height predicted for linear growth and only accounted for $20 \%$ of total variance. We conclude that linear growth occurs early in severely malnourished children but that knemometry behaves as a ponderal index acutely.
\end{abstract}

Linear growth: Knemometry: Malnutrition

Rehabilitation from severe malnutrition is associated with rapid weight gain but linear catch-up growth has been more difficult to demonstrate and a permanent height deficit (stunting) often remains (Khanum et al. 1998). Severity, duration and timing of the nutritional insult determine whether stunting ensues, with those insults under 2 years of age causing maximal impairment of height velocity (Costello, 1989). The promotion of linear catch-up growth in the stunted child requires a prolonged period of ponderal catch-up often not achievable in the environment in which the child is recovering.

Strategies to promote linear growth require an understanding of its relationship to ponderal growth. A retrospective study of growth in 369 hospitalised malnourished children demonstrated linear catch-up growth only in an initially more stunted subgroup, two thirds of whom grew linearly only when they had attained $85 \%$ weight for length (Walker \& Golden, 1988).

Supine and standing length measurement in sick malnourished children may be unreliable and prolonged follow-up is frequently required to estimate change. Lower leg knemometry offers an accurate and precise measure of lower leg growth over a short period (Bisgaard, 1993), but has not been applied to severely malnourished children (Hermanussen, 1988).
$\mathrm{Zn}$ is essential for catch-up growth and immune recovery in severely malnourished children but optimal dosage regimens have not been formulated. We designed a randomised, double blind trial of three $\mathrm{Zn}$ supplementation regimens to study growth and the effect of $\mathrm{Zn}$. This report concentrates on linear and knemometric growth and its relationship to ponderal growth in the early phase of rehabilitation from severe malnutrition.

\section{Patients and methods}

One hundred and forty-one children with severe protein energy malnutrition were sequentially recruited from those admitted to the Dhaka Shishu Children's Hospital Nutritional Rehabilitation Unit in Dhaka, Bangladesh. Children were recruited if aged between 6 and 36 months, had a weight for age less than $60 \%$ of the National Center for Health Statistics reference mean and/or nutritional oedema, were clinically stabilised within 1 week of admission (i.e. able to commence and tolerate oral nutritional rehabilitation regimens), and lived within $2 \mathrm{~h}$ travelling distance of hospital. Children were excluded if there was a clinical suspicion of tuberculosis (contact history, prolonged cough or fever). Informed consent was obtained from the primary carer of each child. 
On recruitment each child entered a standardised clinical and nutritional rehabilitation regimen. All were treated with ampicillin and gentamicin or nalidixic acid or mecillinam if there was a suspicion of invasive diarrhoea, and cloxacillin if skin sepsis was present. The nutritional rehabilitation regimens consisted of milk-based $(264 \mathrm{~kJ}(62 \mathrm{kcal}) ; 2.2 \mathrm{~g}$ protein $/ 100 \mathrm{ml})$ or rice-based $(259 \mathrm{~kJ}(62 \mathrm{kcal}) ; 1 \cdot 1 \mathrm{~g}$ protein $/ 100 \mathrm{ml}$ if diarrhoea present) liquid diets with stepped increases in protein, energy and volume offered depending on presence of oedema and day after recruitment. Children with oedematous malnutrition were commenced on $80 \mathrm{ml} / \mathrm{kg}$ per d or $120 \mathrm{ml} / \mathrm{kg}$ per d and increased incrementally up to $200 \mathrm{ml} / \mathrm{kg}$ per d over the course of their inpatient stay. Feeds were delivered in 2 hourly boluses via gravity feed through a nasogastric tube until appetite recovered to enable the child to take feed orally. Breastfeeding was encouraged and solid food was offered ad libitum.

On admission to the unit all children were given vitamin A (68 mg if over 1 year and $34 \mathrm{mg}$ if under) and commenced on a daily multivitamin supplement after recruitment (1.02 $\mathrm{mg}$ vitamin $\mathrm{A}, 30 \mathrm{mg}$ vitamin $\mathrm{C}, 15 \mu \mathrm{g}$ vitamin $\mathrm{D}, 0.96 \mathrm{mg}$ thiamine, $0.6 \mathrm{mg}$ riboflavin, $0.6 \mathrm{mg}$ pyridoxine and $6 \mathrm{mg}$ of nicotinamide). Fe supplementation was only prescribed if a blood film on day 30 indicated $\mathrm{Fe}$ deficiency.

On recruitment all children were randomised to one of three $\mathrm{Zn}$ supplementation regimens by an independent observer employing variable length blocks within six strata generated by age ( $<13$ months and 13-36 months) and type of malnutrition (marasmus, marasmic kwashiorkor and kwashiorkor). Regimen 1 consisted of zinc sulphate $(1.5 \mathrm{mg} / \mathrm{kg}$ elemental $\mathrm{Zn}$ per $\mathrm{kg}$ body weight) for $15 \mathrm{~d}$ followed by a placebo for $15 \mathrm{~d}$; regimen 2 consisted of zinc sulphate $6.0 \mathrm{mg} / \mathrm{kg}$ for $15 \mathrm{~d}$ followed by placebo for $15 \mathrm{~d}$; regimen 3 consisted of zinc sulphate $6 \cdot 0 \mathrm{mg} / \mathrm{kg}$ for $30 \mathrm{~d}$. These regimens were chosen to represent the spectrum of opinion concerning the $\mathrm{Zn}$ requirement of these children evident from the dosage regimens employed in previously published supplementation trials in this age group.

The average length of inpatient stay in this unit for nontrial children was $11 \mathrm{~d}$ and reflected both the intense social pressure on mothers to leave hospital as quickly as possible and a general move away from inpatient- to outpatientbased rehabilitation. All children in the trial were inpatients for $15 \mathrm{~d}$ after recruitment and received intensive nutritional rehabilitation and health education. Outpatient assessment occurred on days $21,30,45,60,75$ and 90 when morbidity and anthropometric data were collected and health education re-enforced.

Ethical approval was obtained from the Paediatrics and Reproductive Medicine Research Ethics Sub-Committee of Lothian Health, Edinburgh, and the Ethics Committees of the International Centre for diarrhoeal Disease Research, Bangladesh and the Dhaka Shishu Children's Hospital.

Whilst they were inpatients children's weights were recorded daily, knemometry on alternate days and all other anthropometric variables on days 1,8 and 15 . As outpatients all variables were recorded on the morning of follow-up. Lengths and weights were recorded by a team of four nutritionists and four nurses who underwent an 8-week training period before the trial and who were subject to unscheduled formal assessments of technique throughout the study period. Length was recorded supine using a Rollameter (Raven Equipment Ltd, Great Dunmow, Essex, UK) with graduations to $1 \mathrm{~mm}$ and weight was recorded using a Seca electronic scales (model 835, Todd Scales Ltd, Newmarket, UK) with graduations to $20 \mathrm{~g}$. Both were calibrated daily. Knemometry is the measurement of the distance between the child's knee and heel measured with the child sitting and the knee held in flexion of $90^{\circ}$. The mean of five knemometric estimations was used as the measurement. The knemometers were manufactured by the Medical Physics Department of the Royal Infirmary, Edinburgh and measured to $0.1 \mathrm{~mm}$. Knemometry, mid upper arm circumference and skinfold thicknesses were recorded by two observers who also underwent 8 weeks training and were subject to unscheduled formal assessment of technique.

A sample size of sixty was calculated for $90 \%$ power at the $5 \%$ level for anthropometric outcomes. Epi-info v6 (CDC, Atlanta, GA, USA) was employed for data recording, dual entry validation and generation of standard deviation scores ( $z$-score). SPSS (SPSS Inc., Chicago, IL USA) was used for statistical analysis, with Pearson or Spearman correlations used for outcomes after discharge and differences between groups compared using analysis of variance and $t$ tests if the data were normally distributed. Univariate regression analysis were used to identify predictors of change in height for age $z$ score (HAZ) and then construct a stepwise regression model to best predict change.

\section{Results}

One hundred and forty-one children were recruited with a mean (SD) age of 15.4 months (8.7), weight for height $z$ score (WHZ) of $-2.6(0.93)$ and HAZ of $-3.79(1.29)$. Eighty-two children were marasmic, eighteen had kwashiorkor and forty-one had marasmic kwashiorkor with 106 completing follow-up to $90 \mathrm{~d}$. Nineteen children died during the study (thirteen as inpatients), six self discharged, most commonly due to social pressures on the subject's mother preventing her from completing the inpatient phase and ten were lost to follow-up. A study worker visited addresses of defaulters, and information from neighbours suggested that internal migration in Bangladesh back to ancestral villages was responsible. We could not observe the early growth of these children but have no reason to believe that it would have been any different from the rest if they had remained in the study as their day $1 \mathrm{WHZ}$ and HAZ and lower leg length were not significantly different.

As previously reported there were no differences in growth between the three $\mathrm{Zn}$ regimens (Doherty et al. 1998). Day 1 measurements and change in measurements are compared for three age groups in Table 1 . There were statistically significant improvements in weight, length and knemometric length over $90 \mathrm{~d}$ with the majority of this growth taking place after discharge back to the environment in which the children had become malnourished. Mean (SD) change from day 1 to 90 in WHZ was 1.59 (0.85), HAZ (Fig. 1) 0.47 (0.35), knemometric length 
Table 1. Baseline anthropometry and knemometry, type of malnutrition and growth in three age groups of study subjects (Values are means with their standard deviations for $n$ subjects)

\begin{tabular}{|c|c|c|c|}
\hline Age group & $6-12$ months & 13-24 months & 25-36 months \\
\hline Marasmus & 47 & 24 & 11 \\
\hline Marasmic kwashiorkor & 21 & 12 & 8 \\
\hline Kwashiorkor & 12 & 5 & 1 \\
\hline Day $1 \mathrm{WHZ}{ }^{* *}$ & $-2.3(0.9, n 80)$ & $-3.0(0.9, n 41)$ & $-3.1(0.7, n 20)$ \\
\hline Day $1 \mathrm{HAZ}$ & $-3.6(1.1, n 80)$ & $-4 \cdot 1(1 \cdot 6, n 41)$ & $-3.9(1.1, n 20)$ \\
\hline Day 1 knemometry & $15 \cdot 8(1 \cdot 3, n 80)$ & $18 \cdot 0(1 \cdot 6, n 41)$ & $20.7(1 \cdot 7, n 20)$ \\
\hline Days $1 / 45$ WHZ change* & $0.99(0.8, n 65)$ & $1.51(0.6, n 29)$ & $1.16(0.9, n 17)$ \\
\hline Days $1 / 45 \mathrm{HAZ}$ change & $0.18(0.2, n 65)$ & $0.12(0.1, n 29)$ & $0.19(0.2, n 17)$ \\
\hline Days $1 / 45$ knemometric change & $0.46(0.3, n 65)$ & $0.56(0.3, n 29)$ & $0.47(0.3, n 17)$ \\
\hline Days $45 / 90 \mathrm{WHZ}$ change & $0.53(0.7, n 61)$ & $0.3(0.7, n 26)$ & $0.33(0.5, n 16)$ \\
\hline Days $45 / 90 \mathrm{HAZ}$ change ${ }^{\star \star \star}$ & $0.38(0.3, n 61)$ & $0.22(0.2, n 26)$ & $0.19(0.2, n 16)$ \\
\hline Days $45 / 90$ knemometric change & $0.58(0.3, n 61)$ & $0.45(0.4, n 26)$ & $0.53(0.4, n 16)$ \\
\hline Day $90 \mathrm{WHZ} \dagger$ & $-0.74(1.1, n 61)$ & $-1.28(1 \cdot 1, n 26)$ & $-1.63(0.78, n 16)$ \\
\hline Day 90 HAZ†† & $-2.99(1.0, n 61)$ & $-3.93(1.8, n 26)$ & $-3.7(1.0, n 16)$ \\
\hline Day 90 knemometry††† & $16 \cdot 9(1.2, n 61)$ & $18 \cdot 6(1.9, n 26)$ & $21.6(1.5, n 16)$ \\
\hline
\end{tabular}

HAZ, height for age $z$ score; WHZ, weight for height $z$ score.

${ }^{*}$ Days $x / y$ is day $y$-day $x$.

ANOVA between age groups ${ }^{\star \star} P 0.000,{ }^{\star \star \star} P 0.003$.

Paired samples $t$ test between day 1 and $90 \dagger P=0.000, \uparrow \dagger P=0.000, \uparrow \dagger \uparrow P=0.000$.

(Fig. 2) $10 \cdot 3 \mathrm{~mm}(4 \cdot 5)$, mid upper arm circumference $1.6 \mathrm{~cm}(1.3)$, triceps skinfold thickness $1.8 \mathrm{~mm}(1.2)$ and subscapular skinfold $1.6 \mathrm{~mm}(1 \cdot 0)$. Those in the $6-12$ month age group were less wasted initially and had significantly $(P=0.003)$ better linear growth in the second half of the study.

Knemometric technique was assessed throughout the trial on a total of 130 measurements. The technical error for each measurement was derived from the standard deviation of the set of five estimations that made up each measurement. The mean technical error was $0.6 \mathrm{~mm}$ or approximately equivalent to $5 \mathrm{~d}$ growth in this group of children. Knemometric growth correlated significantly $(P<0.01$ or $P<0.001)$ with change in ponderal indices such as mid upper arm circumference, triceps skinfold

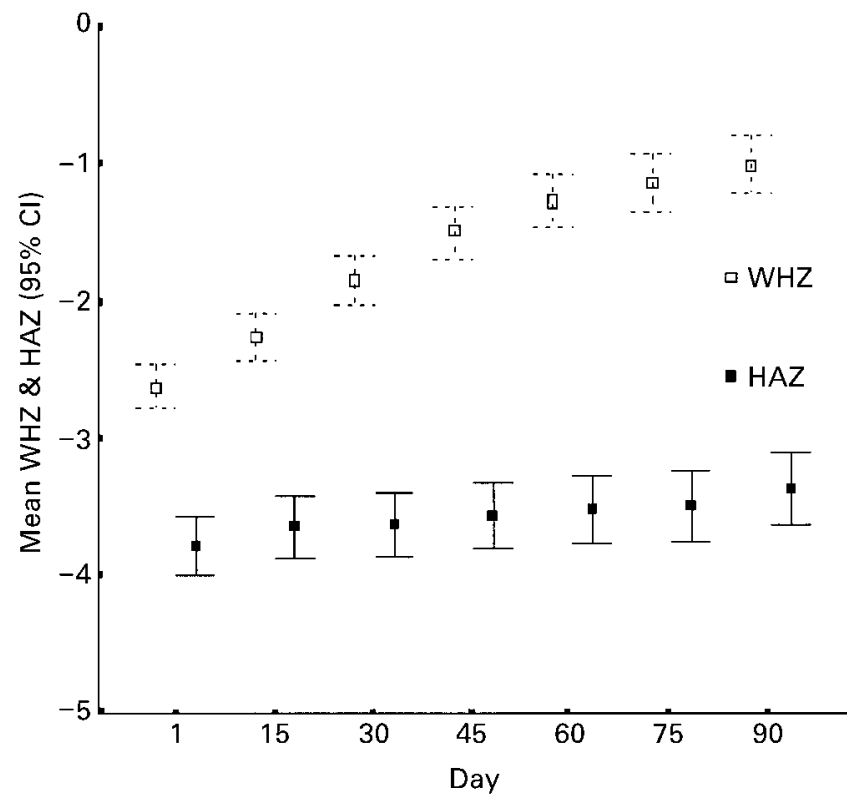

Fig. 1. Weight for height $z$ score $(\mathrm{WHZ})$ and height for age $z$ score (HAZ). thickness, WHZ over all time periods but correlated significantly with change in height for age only after day $45(P<0.001$; Table 2)

To examine the relationship between ponderal and linear growth (Fig. 3) we plotted mean linear growth over the subsequent $30 \mathrm{~d}$ against initial WHZ for all children at every time point. This demonstrated a strong correlation between WHZ and subsequent linear growth $(r 0.3, P<$ $0 \cdot 001)$. Linear growth occurred in the presence of severe wasting and no threshold WHZ could be identified.

Growth is predominately ponderal initially in severely malnourished children and linear growth occurs when WHZ approaches the median National Center for Health Statistics reference (Fig. 4). Univariate regression analysis was used to identify predictors of linear growth and to then

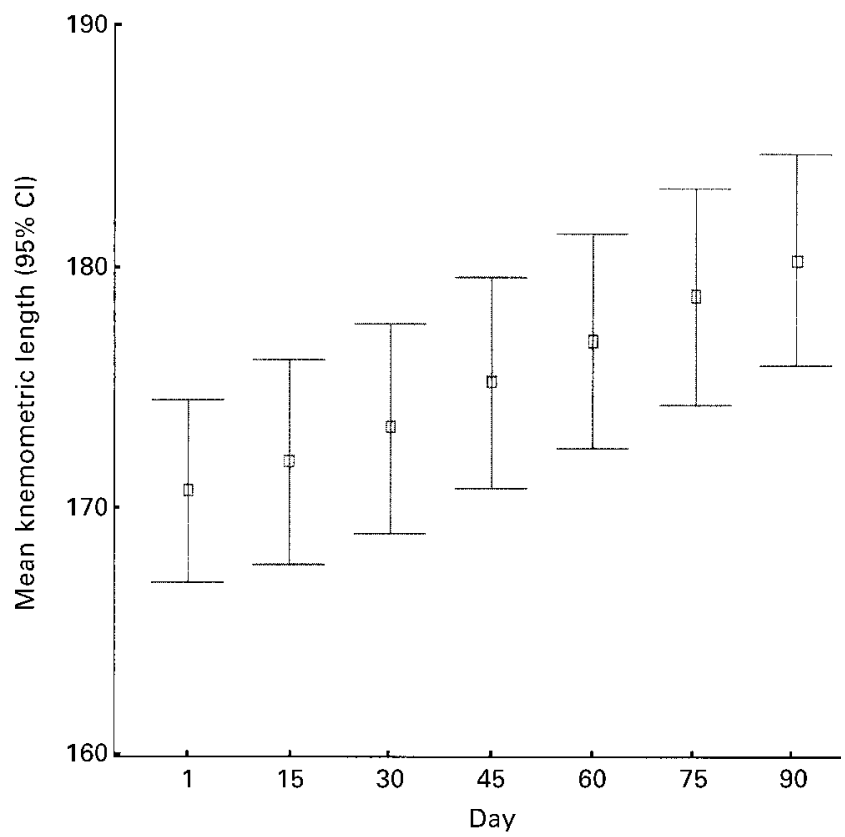

Fig. 2. Knemometric length. 
Table 2. Correlation coefficients between changes in knemometry versus changes in other anthropometric indices between day 1 and subsequent measurement days

\begin{tabular}{|c|c|c|c|c|}
\hline Day & TSFT & MUAC & WHZ & HAZ \\
\hline 15 & $0.32^{\star \star \star}$ & $0.44^{\star \star \star}$ & $0.49^{\star \star \star}$ & -0.14 \\
\hline 30 & $0.31^{\star *}$ & $0.34^{\star \star \star *}$ & $0.51^{\star \star \star *}$ & 0.16 \\
\hline 45 & $0.3^{\star *}$ & $0.38^{\star \star *}$ & $0.55^{\star \star \star}$ & $0.19^{\star}$ \\
\hline 60 & $0.41^{\star \star \star}$ & $0.43^{\star \star \star}$ & $0.56^{\star \star \star}$ & $0.49^{\star \star \star}$ \\
\hline 90 & $0.37^{\star \star \star}$ & $0.39^{\star \star \star}$ & $0.48^{\star \star \star}$ & $0.47^{\star \star \star}$ \\
\hline
\end{tabular}

construct a linear regression model. Only maternal height and day 1 WHZ were predicted in our model and only accounted for $20 \%$ of total variance (Tables 3 and 4 ).

\section{Discussion}

This study was designed to measure linear growth, assess both its relationship to ponderal growth and the effect of three regimens of $\mathrm{Zn}$ supplementation in the early phase of rehabilitation of severely malnourished children. We have previously reported that high dose supplementation $(6.0 \mathrm{mg} / \mathrm{kg}$ per $\mathrm{d})$ was associated with increased mortality and offered no anthropometric benefit over the low dose regimen (Doherty et al. 1998). We shall concentrate in this discussion on early linear growth (both knemometric and change in HAZ), its influences and relationship to ponderal growth.

Catch-up growth in severely malnourished children can be spectacular with growth rates rarely achieved in other physiological circumstances. In this group of wasted and stunted children the mean WHZ improved to $1 z$ score below the reference median over $90 \mathrm{~d}$ with most ponderal growth occurring early and then slowing as children approached the reference median.

Linear catch up of $0.5 z$ scores was demonstrated over

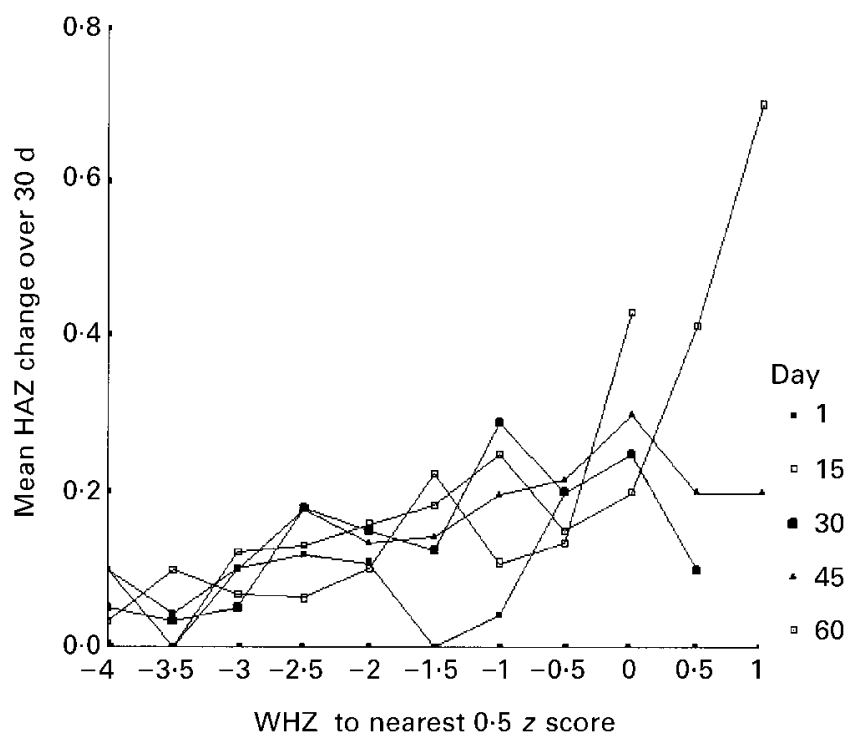

Fig. 3. Mean change in height for age $z$ score (HAZ) in the subsequent $30 \mathrm{~d}$ against initial weight for height $z$ score (WHZ) for all time points $(r 0.3, P<0.001)$.
$90 \mathrm{~d}, 50 \%$ of this catch-up took place in the last $30 \mathrm{~d}$ of the study. Linear growth occurred even in severely wasted children (Fig. 3) with no threshold identified. With increased wasting growth was predominately ponderal and linear growth only approached ponderal when initial WHZ was $1 z$ score below median (Fig. 4). Linear and ponderal growth do occur concurrently with initial WHZ determining whichever predominates. Children in the youngest age group demonstrated most linear catch-up. There were no significant differences in the degree of initial stunting between age groups nor in ponderal catchup growth but the 6-12 month age group had significantly better initial WHZ. Whether interventions designed to promote linear growth act via improving ponderal growth to that point where linear growth predominates or allow for linear growth at a lower initial WHZ is not clear. The switch to skeletal growth, lean tissue deposition and linear growth is not understood, but $\mathrm{Zn}$ supplementation promotes lean tissue deposition (Golden \& Golden, 1992) and thus has been postulated to preferentially promote linear growth.

Identifying predictors of linear growth in these children is difficult. Change in WHZ preceding linear growth has previously been described as a predictor (Walker et al. 1996) but did not predict in our model, possibly because we

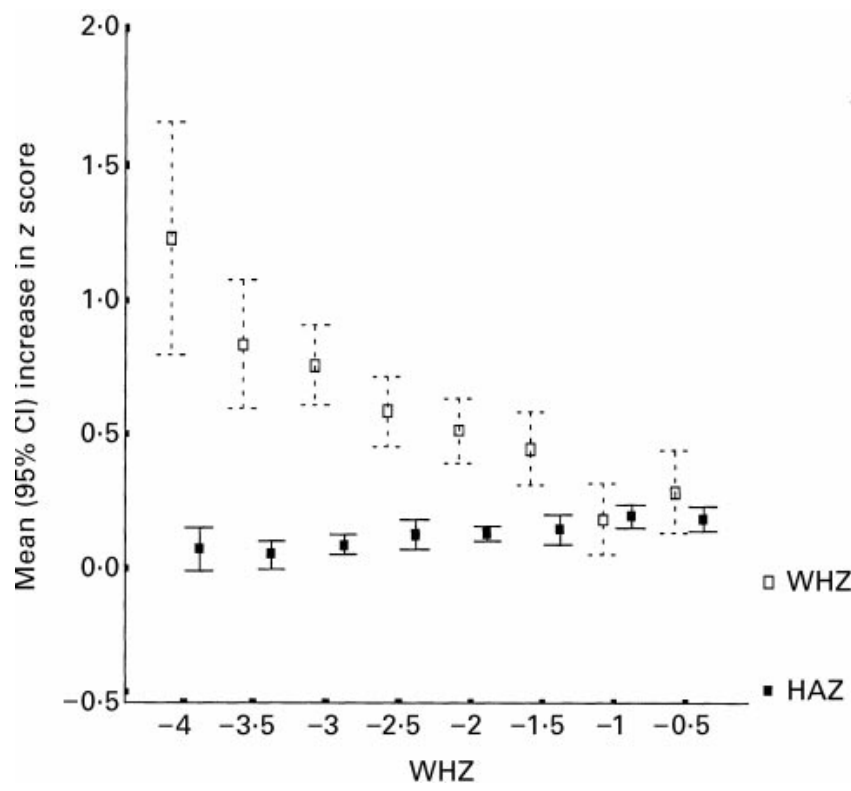

Fig. 4. Weight for height $z$ score $(\mathrm{WHZ})$ and height for age $z$ score (HAZ) increase over $30 \mathrm{~d}$ against initial WHZ (to nearest $0.5 \mathrm{z}$ score) for all time points. 
Table 3. Univariate regression analysis for change in HAZ over $90 \mathrm{~d}$

\begin{tabular}{lll}
\hline Sex & $y=0.45+0.013(-0.12,0.14) x$ & $P 0.85$ \\
Type of malnutrition & $y=0.39+0.05(-0.04,0.14) x$ & $P 0.253$ \\
Age & $y=0.62-0.01(-0.02,-0.003) x$ & $P 0.008$ \\
WHZ day 1 & $y=0.79+0.12(0.06,0.19) x$ & $P 0.0001$ \\
HAZ day 1 & $y=0.5+0.01(-0.04,0.06) x$ & $P 0.73$ \\
WHZ change over 90 d & $y=0.39+0.05(-0.02,0.13) x$ & $P 0.17$ \\
Maternal height & $y=-1.96+1.65(2.7,0.01) x$ & $P 0.009$ \\
Maternal BMI & $y=0.11+0.02(-0.01,0.03) x$ & $P 0.25$ \\
\hline
\end{tabular}

$\mathrm{HAZ}$, height for age $z$ score; $W H Z$, weight for height $z$ score.

Table 4. Linear regression model of change in HAZ over $90 \mathrm{~d}$

\begin{tabular}{|c|c|c|c|c|c|c|}
\hline & & SE & Sum of squares & df & Mean square & $P$ \\
\hline Constant & -1.49 & 0.88 & & & & \\
\hline WHZ day 1 & 0.122 & 0.036 & & & & 0.001 \\
\hline Maternal height & 1.54 & 0.59 & & & & 0.01 \\
\hline Regression & & & 1.66 & 4 & 0.83 & $<0.0001$ \\
\hline Residual & & & $6 \cdot 88$ & 70 & 0.09 & \\
\hline Total & & & 8.5 & 74 & & \\
\hline
\end{tabular}

$\mathrm{HAZ}$, height for age $z$ score; WHZ, weight for height $z$ score; df, degrees of freedom.

looked at early linear growth over 3 months only. Initial WHZ and maternal height did predict but only accounted for $20 \%$ of total variance. Early linear growth is very difficult to predict in these severely malnourished children.

Knemometry has been used in well nourished children as an index of linear growth (Wales \& Milner, 1987); however the relationship between total linear growth and knemometric growth is not clear as different parts of the skeleton appear to grow at different rates and times (Roche, 1974). Knemometric growth occurred early, and only after $45 \mathrm{~d}$ did knemometric growth correlate with change in HAZ. However, across all time periods, knemometric growth correlated positively with change in mid upper arm circumference, triceps skinfold thickness and WHZ. The knemometric measurements overall therefore behaved more as an index of ponderal than linear growth particularly in the first $45 \mathrm{~d}$ of the study. As well as measuring changes in the length of the tibia and fibula the knemometer also measures changes in the soft tissues overlying these. The deposition of fat in the suprapatellar and heel fat pads as well as changes in tissue oedema contributed to measurements. Knemometry offers an accurate and reproducible index of lower leg growth and is a useful index of short-term changes in growth rate (Hermanussen et al. 1987; Wales \& Milner, 1987). However, in this group of children it could not be used as an index of linear growth.

In summary, early linear growth is difficult to predict but does occur even in the presence of severe malnutrition and is strongly correlated with initial WHZ. The knemometer is of limited use as an index of linear growth in this group of children.

\section{Acknowledgements}

We thank all the parents of the children, the project nurses and nutritionists and the staff of the Shishu Hospital, Bangladesh and Nestle UK. We particularly thank Nasreen Banu, Dr Fazlu Haque and Professor M. S. Akbar of the
Shishu Hospital as well as Drs Aminul Islam and George Fuchs of the International Center for Diarrhea Disease Research, Bangladesh and Professor Lawrence Weaver at the Department of Child Health, University of Glasgow.

\section{References}

Bisgaard H (1993) Systemic activity of inhaled topical steroid in toddlers studied by knemometry. Acta Paediatrica 82, 10661071.

Costello AM (1989) Growth velocity and stunting in rural Nepal. Archives of Disease in Childhood 64, 1478-1482.

Doherty CP, Sarkar MAK, Shakur MS, Ling SC, Elton RA \& Cutting WA (1998) Zinc and rehabilitation from severe protein-energy malnutrition: Higher-dose regimens are associated with increased mortality. American Journal of Clinical Nutrition 68, 742-748.

Golden BE \& Golden MHN (1992) Effect of zinc on lean tissue synthesis during recovery from malnutrition. European Journal of Clinical Nutrition 46, 697-706.

Hermanussen M (1988) Knemometry, a new tool for the investigation of growth. European Journal of Pediatrics 147, $350-355$.

Hermanussen M, Geiger-Benoit K, Burmeister J \& Sippell WG (1987) Can the knemometer shorten the time for growth rate assessment? Acta Paediatrica Scandinavica-Supplement 337, 30-36.

Khanum S, Ashworth A \& Huttly SR (1998) Growth, morbidity, and mortality of children in Dhaka after treatment for severe malnutrition: a prospective study. American Journal of Clinical Nutrition 67, 940-945.

Roche AF (1974) Differential timing of maximum length increments among bones within individuals. Human Biology 46, 145-157.

Wales JK \& Milner RD (1987) Knemometry in assessment of linear growth. Archives of Disease in Childhood 62, 166-171.

Walker SP \& Golden MHN (1988) Growth in length of children recovering from severe malnutrition. European Journal of Clinical Nutrition 42, 395-404.

Walker SP, Grantham-McGregor SM, Himes JH \& Powell CA (1996) Relationships between wasting and linear growth in stunted children. Acta Paediatrica 85, 666-669. 